\title{
Richness, structure and functioning in metazoan parasite communities
}

\author{
David Mouillot, Mario George-Nascimento and Robert Poulin
}

Mouillot, D., George-Nascimento, M. and Poulin, R. 2005. Richness, structure and functioning in metazoan parasite communities. - Oikos 109: 447-460.

\begin{abstract}
Ecosystem functioning, characterized by components such as productivity and stability, has been extensively linked with diversity in recent years, mainly in plant ecology. The aim of our study was thus to quantify general relationships between diversity, community structure and ecosystem functions in metazoan parasite communities. We used data on parasite communities from 15 species of marine fish hosts from coastal Chile. The volumetric abundance (volume of all parasite species per individual host, in $\mathrm{mm}^{3}$ ) was used as a surrogate for productivity. Species diversity was measured using both species richness and evenness, while community structure was estimated using the co-occurrence indices V-ratio, C-score and a new C-score index standardized for the number of host replicates. After correcting for fish size, $47 \%$ of host species show no relationship, $13 \%$ show a hump shaped curve and $40 \%$ show positive monotonic relationships between productivity and parasite richness across all host individuals in a sample. We obtained a logarithmically decreasing relationship between evenness and productivity for all fish species, and propose a 'dominance-resistance' hypothesis based on immunity to explain this pattern. The stability of the parasite community, measured as the coefficient of variation in productivity among individual hosts, was strongly and positively related to mean species richness across the 15 host species. The C-score $\mathrm{s}$ index, based on the number of checkerboard units in the host-parasite presence/absence matrix, increases linearly with mean productivity across the 15 host species, suggesting that parasite communities tend to be more structured when they are more productive. This is the likely reason why linear relationships between richness and productivity were not observed consistently in all fish species. Parasite communities provide some clear patterns for the diversity-ecosystem functioning debate in ecology, although other factors, such as the history of community assembly, may also influence these patterns.
\end{abstract}

D. Mouillot, UMR CNRS-UMII 5119 Ecosystèmes Lagunaires, Univ. Montpellier II CC 093, FR-34095 Montpellier Cedex 5, France (mouillot@univ-montp2.fr). - M. GeorgeNascimento, Depto de Ecología Costera, Facultad de Ciencias, Univ. Católica de la Santísima Concepción, Casilla 297, Concepción, Chile. - R. Poulin, Dept of Zoology, Univ. of Otago, P.O. Box 56, Dunedin, New Zealand.

Despite numerous studies, the link between diversity and ecosystem functioning remains highly controversial (Aarssen 1997, Huston 1997, Wardle et al. 1997, Loreau et al. 2001, Wardle 2001a,b, Schmid 2002, Leps 2004). For example, the complexity of cause and effect and the influence of scale or environmental variables in biodiversity and ecosystem functioning (hereafter BEF) relations (Weiher 1999, Bond and Chase 2002, Pfisterer and Schmid 2002, Rajaniemi 2003) lead to some fundamental questions that remain unsolved: which factor drives the relation? Are the relations found in experiments relevant for field studies? How should biodiversity be estimated? Which ecological processes are involved in $\mathrm{BEF}$ relations? Is community structure related to ecosystem functioning? Thus, in BEF research, the question is no longer whether biodiversity matters, but how it matters (Rosenfeld 2002, Naeem and Wright 2003).

The last question deals with the relation between community structure and ecosystem functioning. The

Accepted 8 November 2004 
easiest way to investigate this relation is to consider the two main estimators of its two components: species richness and ecosystem productivity. Species richness is often expected to increase and then decrease with productivity to produce a humpshaped or unimodal relationship (Grime 1973, Huston 1979, Huston and DeAngelis 1994). However, some studies have pointed out that humpshaped relationships between richness and productivity are not the universal rule in natural communities and that other patterns are often observed (Waide et al. 1999, Mackey and Currie 2001, Mittelbach et al. 2001). Another key property of any ecosystem is its stability, i.e. its ability to provide a constant performance over time or across replicates and thus a constant economic value in the case of exploited ecosystems (Armsworth and Roughgarden 2003). A consensus is now emerging for a positive relationship between stability and species richness in field studies (Bai et al. 2004) in experiments (Givnish 1994, Tilman and Downing 1994, Naeem 2002) and in theoretical investigations (Doak et al. 1998, Ives et al. 1999, Loreau 2000, Ives and Hughes 2002) although this relation is influenced by other factors (Ives and Hughes 2002, Pfisterer and Schmid 2002, Wardle and Grime 2003). Thus, the relations between richness, productivity and stability are in need of further investigation, but the next advances in $\mathrm{BEF}$ research may involve the relation between community structure and ecosystem properties.

In this study, we use two ways to account for community structure. Firstly, diversity is a measure of community structure but one can argue that to capture the diversity of a community in a single number is impossible (Ludwig and Reynolds 1988). It is therefore helpful to decompose biodiversity into two or more facets which can then be quantified (Purvis and Hector 2000). There are two major components of species diversity: species richness and species evenness (the latter incorporating data on abundance). The former has been used almost exclusively in earlier BEF research (Loreau 2000, Naeem et al. 2000, Loreau and Hector 2001, Wardle 2001a, Pfisterer and Schmid 2002). A second facet of diversity is evenness, i.e. whether abundances are evenly distributed among species. Based on recent studies of the relationship between evenness and ecosystem functioning (Wilsey and Polley 2002, Polley et al. 2003, Mulder et al. 2004), we can hypothesize that evenness patterns are not independent of ecosystem properties. A second way to investigate community structure is to use null models (Gotelli 2000, Gotelli and Entsminger 2003). Based on co-occurrence patterns, community structure indices (C-Score or V-ratio) and randomisation procedures, this method allows testing species interaction hypotheses among replicates. Some interesting results have already been obtained with cooccurrence patterns in both parasite and ant communities (Gotelli and Ellison 2002a, Gotelli and Rohde
2002, Sanders et al. 2003). Species coexistence rules, even if often studied purely for their own patterns, certainly need to be related to community functioning.

As a generalization of the richness-productivity relationship studies, we propose to focus on relations between community structure (through indices such as richness, evenness, C-Score or V-ratio) and key ecosystem functions, i.e. productivity and stability. Measuring productivity is often a problem, e.g. in plant studies because of below ground biomass estimation, and it is always difficult to deal with stability in animal studies because of sampling errors and naturally high variability among replicates. Parasite communities have been proposed as model systems for tests of community structure because they alleviate many of these problems (Holmes and Price 1986, Naeem and Hawkins 1994, Gotelli and Rohde 2002): each host individual harbours a replicate parasite community, many replicates can be sampled, and the biomass of each parasite species can be collected. Moreover, the demographic processes giving rise to assemblages of metazoan macroparasites of vertebrate hosts are similar across all the parasite species in the community: the population dynamics of macroparasites are open systems driven by recruitment (Poulin 1998). For all these reasons, parasite communities are useful model ecosystems to test the productivitydiversity relationship and more generally to pursue BEF research.

In an analysis across host samples from 131 species of vertebrates, Poulin et al. (2003) found a positive linear relationship between the number of metazoan parasite species per sample and the mean parasite biomass per host species. In heterotrophs, productivity is the rate of organic matter accumulation, and is often difficult to measure; for this reason, biomass is often used as a surrogate measure, one that is particularly adequate for systems with rapid turnover of individuals. How parasite species richness and parasite biomass (or productivity) covary among individual hosts of the same species has not been documented yet, although the two are likely to correlate positively. Still, two other important questions remain. First, what drives the relationship? Demonstrating that parasite species co-occur at random, i.e. that parasite communities are unstructured, would support species richness as the driver of the richnessproductivity relationship because the accumulation of new parasite species by a host individual would be independent of the species already established, with each species contributing to total parasite biomass. The second question regarding the richness versus productivity relationship among parasite communities in individual hosts concerns its shape. Across host species, the richness-productivity (or biomass) relationship is positive and linear (Poulin et al. 2003). Among individuals within host species, once the influence of host body size is removed, it could either also be positive and 
monotonic if species interactions are weak, or peak at intermediate productivity values if a few parasite species come to dominate the community at energy-rich levels. Another community property is expected to covary with species richness, one that is of fundamental importance and that has never been investigated in parasite communities: stability. A simple operational definition of stability is to equate it with variability (McCann 2000). The variability in parasite biomass among individual hosts in a population, measured as the coefficient of variation, can serve as an estimate of stability: it estimates how variable the whole parasite community is among the patches (host individuals) that it occupies. Are parasite communities characterised by high species richness more or less stable than those with low species richness? This important question has never been addressed in parasite communities.

Using parasite communities, we can relate assembly or coexistence rules and ecosystem processes. Thus, the aims of our study were: (1) to assess the shape of the relationship between parasite species richness and productivity (parasite biomass) across individual hosts from the same population, i.e. across parasite infracommunities (sensu Bush et al. 1997); (2) to investigate how evenness of parasite communities varies with both productivity and host size; (3) to quantify the relationship between variability in parasite biomass and species richness, across different but comparable component communities of parasites from different host species; (4) to examine patterns of parasite species co-occurrence among individual hosts and determine whether they depart from null models; and (5) to search for correlations between structure (co-occurrence indices), stability and mean productivity of parasite communities among different host species and determine what kind of relations exist, if any. To achieve these objectives, we used data from more than 1000 individual hosts of 15 fish species. We included all metazoan parasites in or on each host individual; since the host is the resource unit considered here, it did not matter whether the parasites were external or internal. Our results highlight clearcut patterns, and show how species richness and community structure are important determinants of community functioning in parasite communities and vice versa.

\section{Materials and methods}

\section{Data collection}

Adult fishes of 15 marine species were sampled off the coast of Chile (Table 1). In each of the 15 fish species, each individual fish was dissected and searched for metazoan ecto- or endoparasites using standard procedures. The volumetric abundance (volume of all parasite species per host, in $\mathrm{mm}^{3}$ ) was used as a surrogate for biomass. The body volume of each taxon was approximated using either of the following methods. For the small parasites, body volume was determined by measuring maximum length and diameter and computed assuming a regular body shape for the parasite (e.g. cylindrical for nematodes and acanthocephalans, ellipsoid for digeneans and some cestodes, cylindrical with an ovoid base for other cestodes, etc.). For largesized parasites or those of irregular shape, body volume was determined by volume displacement in a graduated container. More details on these data are given in George-Nascimento et al. (2002, 2004).

\section{Diversity-functioning relationships}

\section{Diversity estimators}

While species richness is the easiest and most natural way to summarize diversity, this number does not take into account all the community structure and more particularly the distribution of abundance among species (Frontier 1985, Magurran 1988, Mouillot et al. 2000). Ideally, a second indicator for diversity would be independent from the first one by adding totally new information. Thus, we chose to calculate evenness, which measures the regularity of abundance among species independently of species richness (Magurran 1988); its value is one when all species have exactly the same abundance. Abundance is usually equated with density in animal studies (Tokeshi 1993) but it can be estimated with various metrics (Mouillot et al. 2001). When dealing with the productivity of the community, it is misleading to use density because this implies that an individual weighing a few micrograms has the same importance as an individual of several grams. In our study abundance of each species is measured by its biovolume which is proportional to biomass. Among the numerous evenness indices available, we chose the Bulla (1994) "O" as a measure of evenness because it meets the requirements of Smith and Wilson (1996) and has a good discrimination power between communities (Mouillot and Wilson 2002). With $S$ being the number of species and $p_{i}$ their relative volumetric abundances, this index is:

$\mathrm{O}=\sum_{\mathrm{i}=1}^{\mathrm{S}} \min \left(\mathrm{p}_{\mathrm{i}}, 1 / \mathrm{S}\right)$

Thus, two complementary facets of diversity are quantified in our analysis: richness and evenness (Purvis and Hector 2000).

\section{Ecosystem functioning estimators}

In this study, we look at the diversity-productivity relationship at the within-host-species scale. Here the productivity will be taken as the biovolume of the parasite infracommunity, itself a surrogate of biomass. 
Table 1. Number of hosts examined and mean (standard deviation) of parasite species richness, evenness and biovolume and mean (SD) (COV) of fish size per individual host fish. Evenness is not estimated when we have too few species in the parasite infracommunities $(<4$ on average).

\begin{tabular}{|c|c|c|c|c|c|}
\hline Host species & $\begin{array}{l}\text { Number } \\
\text { of host }\end{array}$ & $\begin{array}{l}\text { Fish size } \\
\quad(\mathrm{cm})\end{array}$ & $\begin{array}{l}\text { Parasite biovolume } \\
\text { (mm3) }\end{array}$ & $\begin{array}{l}\text { Parasite } \\
\text { richness }\end{array}$ & $\begin{array}{l}\text { Parasite } \\
\text { evenness }\end{array}$ \\
\hline Dissostichus eleginoides & 49 & $108.02(20.87)(0.19)$ & 1203.99 (1292.17) & $6.49(1.63)$ & $0.37(0.12)$ \\
\hline Merluccius australis & 409 & $67.62(10.41)(0.15)$ & $420.00(448.50)$ & $3.50(1.27)$ & \\
\hline Macruronus magellanicus & 147 & $62.14(6.83)(0.11)$ & $172.20(142.91)$ & $3.76(1.52)$ & \\
\hline Eleginops maclovinus & 75 & $42.83(7.31)(0.17)$ & $61.97(83.31)$ & $3.13(1.32)$ & \\
\hline Cilus gilberti & 29 & $53.42(11.14)(0.21)$ & $466.11(314.34)$ & $8.90(2.50)$ & $0.40(0.14)$ \\
\hline Prolatilus jugularis & 35 & $28.37(2.49)(0.09)$ & $26.59(18.23)$ & $4.28(1.58)$ & $0.68(0.15)$ \\
\hline Pinguipes chilensis & 29 & $38.29(3.45)(0.09)$ & $111.55(53.06)$ & $5.41(1.45)$ & $0.48(0.14)$ \\
\hline Brama australis & 26 & $41.76(3.80)(0.09)$ & $741.74(555.80)$ & $4.38(1.60)$ & $0.47(0.12)$ \\
\hline Thyrsites atun & 18 & $58.58(9.34)(0.16)$ & $18.71(44.70)$ & $1.94(1.40)$ & \\
\hline Scomber japonicus & 68 & $39.74(2.87)(0.07)$ & $202.07(502.21)$ & $1.88(0.92)$ & \\
\hline Seriolella violacea & 20 & $60.94(5.41)(0.09)$ & $3864.53(4092.43)$ & $4.60(1.54)$ & $0.36(0.15)$ \\
\hline Stromateus stellatus & 35 & $28.81(1.37)(0.05)$ & $68.53(89.11)$ & $2.67(1.28)$ & \\
\hline Genypterus maculatus & 60 & $50.52(12.81)(0.25)$ & $1488.41(2495.07)$ & $2.98(1.07)$ & \\
\hline Genypterus chilensis & 60 & $66.47(5.99)(0.09)$ & $578.31(517.77)$ & $4.87(1.10)$ & $0.43(0.15)$ \\
\hline Genypterus blacodes & 60 & $73.14(8.14)(0.11)$ & $2141.02(1375.74)$ & $6.27(1.53)$ & $0.43(0.19)$ \\
\hline
\end{tabular}

For the richness-stability relationship, the analysis was performed across host species $(\mathrm{N}=15)$. We used the mean parasite species richness per host individual (mean infracommunity richness) as a measure of richness, and the coefficient of variation in total parasite biomass per host individual as a measure of stability (McCann 2000, Ives and Hughes 2002).

\section{Statistical analysis of the relations}

For the relationship between parasite species richness (R) and productivity (total biovolume of the parasite infracommunity) (P) across host individuals, we first fitted a quadratic linear regression to the data: $\mathrm{R}=\alpha+\beta(\mathrm{P})+\gamma\left(\mathrm{P}^{2}\right)$. If the two coefficients of the regression $(\alpha$ and $\beta)$ are not significantly different from zero, productivity is assumed not to vary with richness. If only the quadratic term $(\gamma)$ doesn't differ from zero the relation is monotonic linear, and the slope defines the direction of the relation. Regressions in which the quadratic term $(\gamma)$ explains a significant amount of variance, after fitting the linear term, have a curvilinear shape. In such cases we also tested for a hump-shaped or peaked curve with the Mitchell-Olds test (Mitchell-Olds and Shawn 1987) already used in major studies on the subject (Waide et al. 1999, Mackey and Currie 2001, Mittelbach et al. 2001, Chase and Leibold 2002). This method (hereafter MOS test) tests whether an unconstrained least squares model with a particular intermediate maximum provides a significantly better fit to the data than a model with a maximum at either the higher or lower end of the range of values. These fitting procedures were applied separately to the data from each of the different host species.

Some confounding variables can influence both parasite richness and productivity, however, in ways that may affect the shape of the relationship between the two. Host body size often correlates positively with parasite species richness across different host species (Poulin 1997, Morand 2000), and it likely also correlates positively with total parasite biovolume. The same may apply among individual hosts within species. Therefore, corrected measures of both parasite species richness and productivity were obtained by taking the residuals of regressions of these two variables against host body size. Testing for linear or humpshaped relationships between parasite species richness and biovolume or productivity was then repeated using corrected values (residuals) for each of the 15 host species.

The evenness-productivity and richness-stability relationships were fitted by a simple linear, a power and a $\log$ linear regression. We retained the best relation, i.e. the one showing the highest coefficient of determination $\left(\mathrm{R}^{2}\right)$, and we accept this relation only if the p-value associated with the $\mathrm{F}$ value of the ANOVA test for linear models is lower than $5 \%$.

\section{Co-occurrence pattern indices}

Several earlier studies have emphasized that most parasite communities appear non-saturated with species, with interspecific competition not playing a major structuring role (Rohde 1991, Poulin 1996, Morand et al. 1999, Gotelli and Rohde 2002, Mouillot et al. 2003). Here we used presence/absence data and analyses on co-occurrence to add information about community structure to our results on species diversity and community functioning through two indices and their randomisation tests.

We chose V-ratio and C-score indices because they are based on two different matrix structure, respectively the average covariance and average co-occurrence, and because they are supposed to be robust to minor changes in community structure (Gotelli 2000). 
The variance ratio (V-ratio) is calculated as the ratio of the variance of the column sums to the sum of the row variances in a parasite species (row) by host individual (column) matrix (Robson 1972, Schluter 1984). If "niche limitation" (Macarthur and Levins 1964, Wilson 1987, Wilson and Roxburgh 1994, 2001, Stubbs and Wilson 2004) constrains the number of coexisting species, the variance in species richness among host individuals will be small relative to the null model (competitively structured community) whereas in a community with high variation in the number of species, the observed variance ratio should be significantly higher than expected by chance (Gotelli and Entsminger 2001). Using the Ecosim software v7.0, we generated a null model setting all row sums fixed (the number of occurrence for each parasite species is assumed to be constant) and all columns equiprobable (each parasite species is assigned randomly to the hosts but only to as many hosts as expected from their prevalence in the samples) as suggested by Gotelli (2000). We computed 5000 randomized matrices and thus 5000 simulated indices to compare our observed V-ratio to the simulated distribution of V-ratios under the null hypothesis to reject or not this hypothesis with a type I error (Gotelli and Graves 1996, Manly 1998). This was repeated separately for each of the 15 host species.

Secondly, to test for the structure of parasite communities, we calculated and tested by randomization the C-score introduced by Stone and Roberts (1990), an index quantifying the average number for each unique species pair of "checkerboard units" in a matrix of occurrence (parasite species $\times$ host individual), i.e. the number of submatrices of the form $01 / 10$ or $10 / 01$. The number of checkerboard units $(\mathrm{CU})$ for each species pair is calculated as $\mathrm{CU}=\left(\mathrm{r}_{\mathrm{i}}-\mathrm{H}\right)\left(\mathrm{r}_{\mathrm{j}}-\mathrm{H}\right)$, where $\mathrm{r}_{\mathrm{i}}$ is the number of occurrences for species $\mathrm{i}$ (over all sampled hosts, i.e. the total of the row corresponding to this species in the matrix) and $r_{j}$ is the number of occurrences for species $\mathrm{j}$, and $\mathrm{H}$ the host number (number of rows). In a competitively structured community, the C-score tends to be larger than expected by chance with a high number of checkerboard units, i.e. with a high segregation of parasite species among hosts. In contrast, when the C-score is low, we have relatively few checkerboard units, i.e. species are more aggregated and the community is not strongly structured by competition rules. To assess whether the p-value for the observed C-score is lower or higher than expected by chance we must compare it to a simulated distribution of C-scores like in all tests of null models (Gotelli and Graves 1996, Manly 1998). As suggested (Gotelli 2000, Gotelli and Ellison 2002a), we used a "fixed-fixed" algorithm to test the C-score statistic. By fixing the sums of rows and columns, we randomly swapped checkerboard units through the presence/absence matrix for each host to generate 5000 new matrices on which we calculated 5000 simulated C-scores using the Ecosim software v7.0. We also repeated this separately for each of the host species.

The above two indices depend on the matrix size, i.e. the number of replicates (here the number of hosts examined) and the number of parasite species (Gotelli and McCabe 2002, Gotelli and Rohde 2002). For example, the $\mathrm{C}$-score is strongly related to the number of infracommunities sampled because this index counts the number of checkerboard units directly linked to the number of units. To avoid this problem, Gotelli and McCabe (2002) proposed to use a standardized effect size (SES) version for each index instead of the original one: $\mathrm{SES}=\left(\mathrm{I}_{\mathrm{obs}}-\mathrm{I}_{\mathrm{sim}}\right) / \mathrm{s}_{\mathrm{sim}}$.

$I_{\text {obs }}$ being the observed index on the data set, $I_{\text {sim }}$ corresponds to the mean of the indices estimated on the simulated matrices under the null hypothesis and $s_{\text {sim }}$ is the associated standard deviation. The standardized indices allow comparison between communities with different sample sizes. Even if SES indices are supposed to be independent from species richness or sample size (Gotelli and McCabe 2002, Gotelli and Rohde 2002) we also use a new index measuring the checkerboard units independently from the number of hosts. It can be shown that the $\mathrm{C}$-score is proportional to the squared number of hosts $\left(\mathrm{H}^{2}\right)$ because this index is a product of the number of occurrences for two species over all the replicates (Gotelli 2000). Thus, if the number of replicated infracommunities increases with a factor IF, the number of possible occurrences and checkerboard units increases by a factor of $\mathrm{IF}^{2}$. Thus the new index we propose is a standardized C-score ${ }_{\mathrm{s}}=100 \mathrm{C}$-score $/ \mathrm{H}^{2}$ to remove the sample size effect, i.e. the number of hosts examined. The coefficient 100 is only used to get results within a range between 0 and 5 .

All the correlations between parasite species richness, the number of hosts and the V-ratio, C-scores, SES indices or $\mathrm{C}$-score $\mathrm{s}_{\mathrm{s}}$ will be examined through the correlation coefficient and its associated test. Subsequently, indices independent from matrix size will be related to community functions (productivity, stability).

\section{Results}

\section{Data summary}

We observed strong variation in host size, total biovolume and richness among the different parasite infracommunities considered (Table 1). The total biovolume of parasite infracommunities varies by a factor of 200 between $T$. atun $\left(18.71 \mathrm{~mm}^{3}\right)$ and $S$. violacea $\left(3864.53 \mathrm{~mm}^{3}\right)$. For species richness, C. gilberti harbours about 9 parasite species per host individual on average whereas the lowest value was observed for S. japonicus with less than 2 species per host on average. Evenness was only estimated for hosts with more than 4 parasite species on average and the values are in the range $0.36-0.68$. 
Correlations between each pair of these variables (size, richness and biovolume as a surrogate for productivity) are shown in Table 2 (top left part) and no one result is statistically significant. Whereas the absence of influence of the number of hosts examined on mean parasite richness or total biovolume (productivity) and host size is not surprising, we found that the size of the host is not significantly related to parasite richness and total biovolume even though the correlation is positive. In the same way, parasite richness and total biovolume of parasite communities are positively related but not significantly. These results are mainly influenced by the $S$. violacea data, this fish having a medium size and medium richness but by far the highest total biovolume (Table 1). Without this host species, results would conform more closely to well known positive relations between host size and parasite biovolume $(\mathrm{r}=0.547, \mathrm{p}<0.05)$.

\section{Does parasite richness have a consistent relationship with productivity?}

The amount of variation in parasite species richness explained by parasite biovolume, assumed here to equate with productivity, varied greatly among the host species studied with a range of $0.2-50 \%$ (Table 3). For 5 species (S. violacea, C. gilberti and the three Genypterus), there is no significant relationship whereas for 9 species we get linear monotonic positive relations between richness and productivity for parasite communities. For only one species (M. australis) the two coefficients of the second order polynomial regression are significantly different from zero and the relation is quadratic; moreover the MOS test revealed a significant hump-shaped curve $(p<0.001)$ for this species only.

Even if the relation was not significant between fish size and productivity or richness (Table 2) we computed the preceding analyses on corrected measures of both species richness and productivity obtained by taking the residuals of regressions of these two variables against host body size. The results are reported in Table 3 and are barely different from those obtained using initial and basic data. Only three species demonstrate a different pattern than the one observed on initial raw values of richness and productivity. $P$. chilensis and $D$. eleginoides now show no relation between productivity and richness while for S. japonicus, the relation between richness and productivity is now significantly hump-shaped $(\mathrm{p}<0.01)$ and is presented in Fig. 1. For the 12 other species, the relation is the same with half of them showing monotonic linear increases like in M. magellanicus (Fig. 1).

\section{Does evenness have a consistent relationship with host size or productivity?}

Regression analyses indicated that species evenness has no consistent relationship with host size in parasite communities. This relation was investigated for eight fish species, the ones with more than four parasite species per infracommunity on average (Table 1). Two species (S. violacea and P. chilensis) do not show any relation between evenness and fish size (Fig. 2). Two species (C. gilberti and G. chilensis) present a significant logarithmically increasing relation whereas the four others show a linear relation between evenness and host size (Fig. 2) but with low coefficients of determination $\left(\mathrm{R}^{2}\right.$; between 0.1 and 0.2$)$.

Analyses on the evenness-productivity relationship for the same eight communities show a clear and consistent logarithmically decreasing relation for all fish species (Fig. 3; p <0.001).

\section{Is community stability related to parasite richness?}

We calculated the coefficient of variation (CV) of the biovolume (productivity) for each host species among all replicates (i.e. all infracommunities). Here, $\mathrm{CV}$ is assumed to be negatively related to the stability, i.e. the more variation we have in biovolume among replicates,

Table 2. Pairwise correlation matrix for the main characteristics of metazoan parasite communities across 15 marine fish species. Richness is the number of parasite species, total parasite biovolume is used a s a surrogate for productivity and CV is the biovolume coefficient of variation among host replicates. Significant correlation coefficients are in bold entries.

\begin{tabular}{|c|c|c|c|c|c|c|c|c|c|}
\hline & $\begin{array}{l}\text { host } \\
\text { number }\end{array}$ & $\begin{array}{l}\text { host } \\
\text { size }\end{array}$ & richness & productivity & $\mathrm{CV}$ & C-score & V-ratio & C-score ${ }_{\mathrm{s}}$ & $\begin{array}{c}\text { SES } \\
\text { C-score }\end{array}$ \\
\hline host size & 0.221 & & & & & & & & \\
\hline richness & -0.173 & 0.395 & & & & & & & \\
\hline productivity & -0.152 & 0.388 & -0.258 & & & & & & \\
\hline $\mathrm{CV}$ & -0.047 & -0.096 & $-0.714^{* *}$ & -0.159 & & & & & \\
\hline C-score & $0.967 * * *$ & 0.205 & -0.133 & -0.094 & -0.044 & & & & \\
\hline V-ratio & -0.133 & 0.102 & $0.569 *$ & 0.038 & $-0.553 *$ & -0.192 & & & \\
\hline C-score ${ }_{\mathrm{s}}$ & -0.143 & $0.519 *$ & 0.222 & $0.553^{*}$ & -0.004 & -0.101 & -0.466 & & \\
\hline SES C-score & 0.228 & 0.107 & -0.153 & -0.195 & 0.055 & 0.164 & -0.282 & 0.092 & \\
\hline SES V-ratio & -0.146 & 0.083 & 0.291 & -0.089 & -0.340 & -0.282 & $0.907 * * *$ & -0.511 & -0.178 \\
\hline
\end{tabular}

$*: \mathrm{p}<0.05 ; * *: \mathrm{p}<0.01 ; * * *: \mathrm{p}<0.001$. 
Table 3. Relationship between species richness and productivity $(\mathrm{R}-\mathrm{P})$ for 15 host fish parasite communities (non significant-, positive monotonic / and hump shaped or peaked $\cap$ ). We used raw data and residuals estimated from the regressions against fish size. $\mathrm{R}^{2}$ is the coefficient of determination for the model and $\mathrm{p}$-value indicates the overall first error value for the regression (based on F ANOVA test) except for non significant results (ns when $\mathrm{p}>0.05$ ).

\begin{tabular}{|c|c|c|c|c|c|c|}
\hline \multirow[t]{2}{*}{ Host species } & \multicolumn{3}{|c|}{ Raw data } & \multicolumn{3}{|c|}{ Residuals } \\
\hline & $\mathrm{R}-\mathrm{P}$ & $\mathrm{R}^{2}(\%)$ & p-value & $\mathrm{R}-\mathrm{P}$ & $\mathrm{R}^{2}(\%)$ & p-value \\
\hline Dissostichus eleginoides & I & 12.7 & 0.0410 & - & 7.2 & $\mathrm{~ns}$ \\
\hline Merluccius australis & $\cap$ & 18.6 & $<0.0001$ & $\cap$ & 17.8 & $<0.0001$ \\
\hline Macruronus magellanicus & i & 46 & $<0.0001$ & i & 42.9 & $<0.0001$ \\
\hline Eleginops maclovinus & I & 21.7 & 0.0001 & l & 16.4 & 0.0016 \\
\hline Cilus gilberti & - & 12.2 & ns & - & 15.9 & ns \\
\hline Prolatilus jugularis & / & 38.3 & 0.0004 & 1 & 22.3 & 0.0175 \\
\hline Pinguipes chilensis & I & 21.9 & 0.0405 & - & 19.8 & ns \\
\hline Brama australis & l & 36.8 & 0.0051 & l & 43 & 0.0015 \\
\hline Thyrsites atun & l & 50 & 0.0053 & I & 51.6 & 0.0043 \\
\hline Scomber japonicus & i & 20.8 & 0.0005 & $\cap$ & 25.6 & $<0.0001$ \\
\hline Seriolella violacea & - & 2.2 & ns & - & 2.7 & ns \\
\hline Stromateus stellatus & I & 27.9 & 0.0053 & I & 28.1 & 0.0051 \\
\hline Genypterus maculatus & - & 2.2 & ns & - & 2.2 & ns \\
\hline Genypterus chilensis & - & 0.2 & ns & - & 2.6 & ns \\
\hline Genypterus blacodes & - & 9.6 & ns & - & 7.3 & ns \\
\hline
\end{tabular}

the lower the stability. We found (Table 2) that $\mathrm{CV}$ is not correlated with either the number of hosts examined $(\mathrm{r}=-0.047, \mathrm{p}>0.05)$ or the average total biovolume of parasite $(\mathrm{r}=-0.152, \mathrm{p}>0.05)$. Across the 15 host species, $\mathrm{CV}$ is clearly decreasing when species richness increases, the curve being well described by a log linear relation $\left(R^{2}=0.71, p<0.0001\right.$; Fig. 4$)$, so it seems that stability of community performance is positively related to the richness of parasite species.
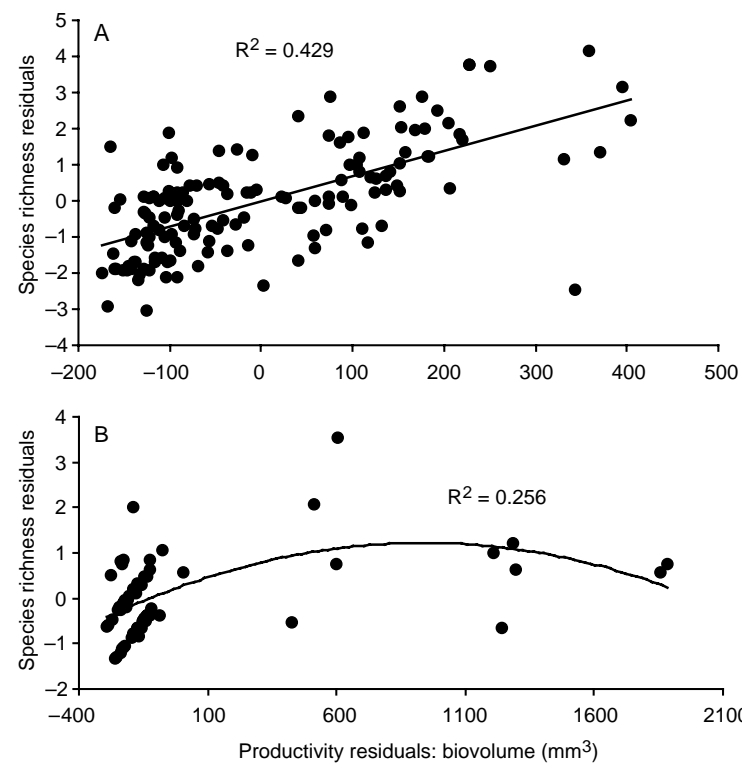

Fig. 1. Two examples of significant richness-productivity relationships on residuals estimated by a regression on fish sizes: a positive monotonic relation for Macruronus magellanicus (A) and a peaked curve for Scomber japonicus (B). Complete statistics for these relations are presented in Table 3 .

\section{What are the assembly rules in parasite community structure?}

For community structure we detected few significant results, i.e. few departures from randomness (Table 4). The C-score index, measuring the mean number of checkerboard units in the occurrence matrix, was found to be higher than expected under the null model hypothesis for only four species: $M$. australis, E. maclovinus, T. atun and G. blacodes. For these four host species, parasite species are highly segregated, showing fewer co-occurrences than expected by chance with the fixed-fixed algorithm.

The results for the V-ratio index indicate that there were seven significant results among the 15 host fish species (Table 4). For D. eleginoides, M. magellanicus and $C$. gilberti, the V-ratio values are significantly higher than expected under the null hypothesis with fixed rows (occurrences of parasite species) and equiprobable columns (all hosts have equal probability to harbour a parasite species). For the latter two species, the result is highly significant $(\mathrm{p}<0.0001)$, thus suggesting a very high aggregation of metazoan parasite species among hosts. In contrast, four species (M. australis, S. japonicus, G. maculatus and G. chilensis) present a lower V-ratio than expected by chance suggesting structured communities.

\section{Are community structure indices related to host characteristics and community functions?}

The main aim of this study is to find relationships between structure and functioning of parasite communities. Therefore we calculated coefficients of correlation between the five co-occurrence indices (two classical and 

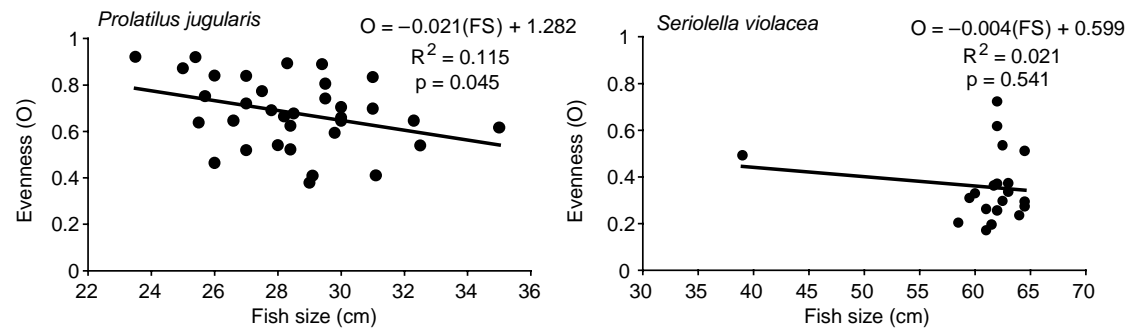

Fig. 2. Relationships between evenness of parasite infracommunities measured by the Bulla index $(\mathrm{O})$ and fish size for parasite communities belonging to eight different hosts.
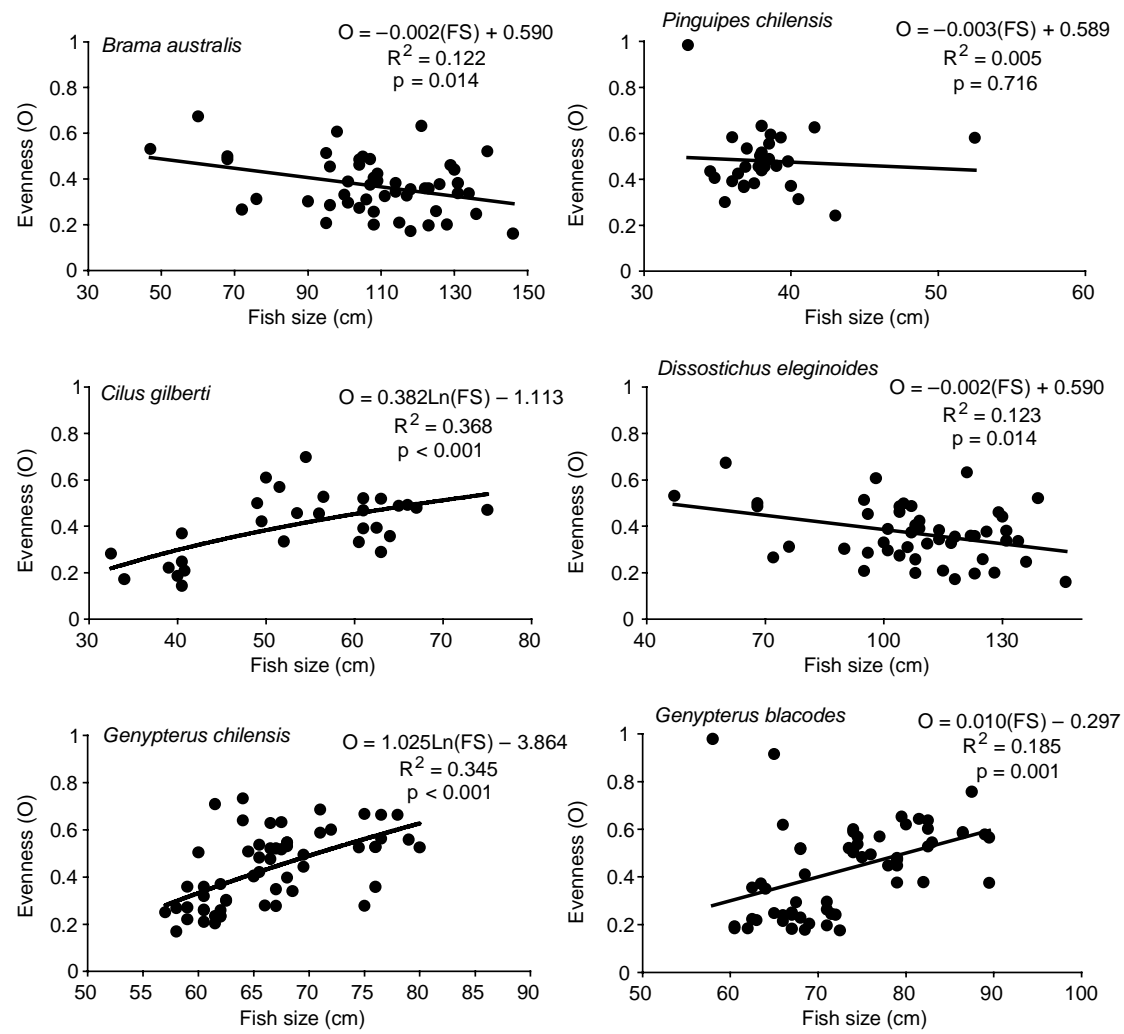

three standardized) and host number, host size, mean parasite richness, mean productivity and stability across the 15 host species. Results in Table 2 show seven significant correlations.

First, the C-score index is strongly and positively correlated with the number of host individuals examined. This is because the $\mathrm{C}$-score estimates the number of checkerboard units, and this number must increase with the number of replicates. We investigate more precisely the relation between the $\mathrm{C}$-score and host number $(\mathrm{H})$. We obtain a strong log-log regression with the C-score increasing by a factor of $\mathrm{H}^{1.97}\left(\mathrm{R}^{2}=0.92, \mathrm{p}<0.001\right)$; this approaches the factor $\mathrm{H}^{2}$ we predicted when developing the $\mathrm{C}$-score index. $_{\text {s }}$

The $\mathrm{C}$-score $\mathrm{s}_{\mathrm{s}}$ is positively related $(\mathrm{p}<0.05)$ to the productivity and host size in our study whereas it is not correlated with host number or species richness
(Table 2), i.e. with the size of the occurrence matrix. This relationship is log-linear in both cases (Fig. 5) thus the competition intensity or other similar forces structuring the parasite community seem to increase with the productivity and host size.

Mean richness is also strongly related to the V-ratio and thus the V-ratio index is not independent from the size of the occurrence matrix and particularly the number of parasite species.

The last two significant correlations are not surprising. The V-ratio is negatively correlated with the coefficient of variation $(\mathrm{CV})$ in productivity because this V-ratio depends of the richness and the CV depends also to the community richness as shown before (Table 2). Finally, the V-ratio is strongly and positively correlated with its own standardized form SES V-ratio. 
Fig. 3. Relationships between evenness of parasite infracommunities measured by the Bulla index $(\mathrm{O})$ and productivity (total parasite biovolume) for parasite communities belonging to eight different hosts.
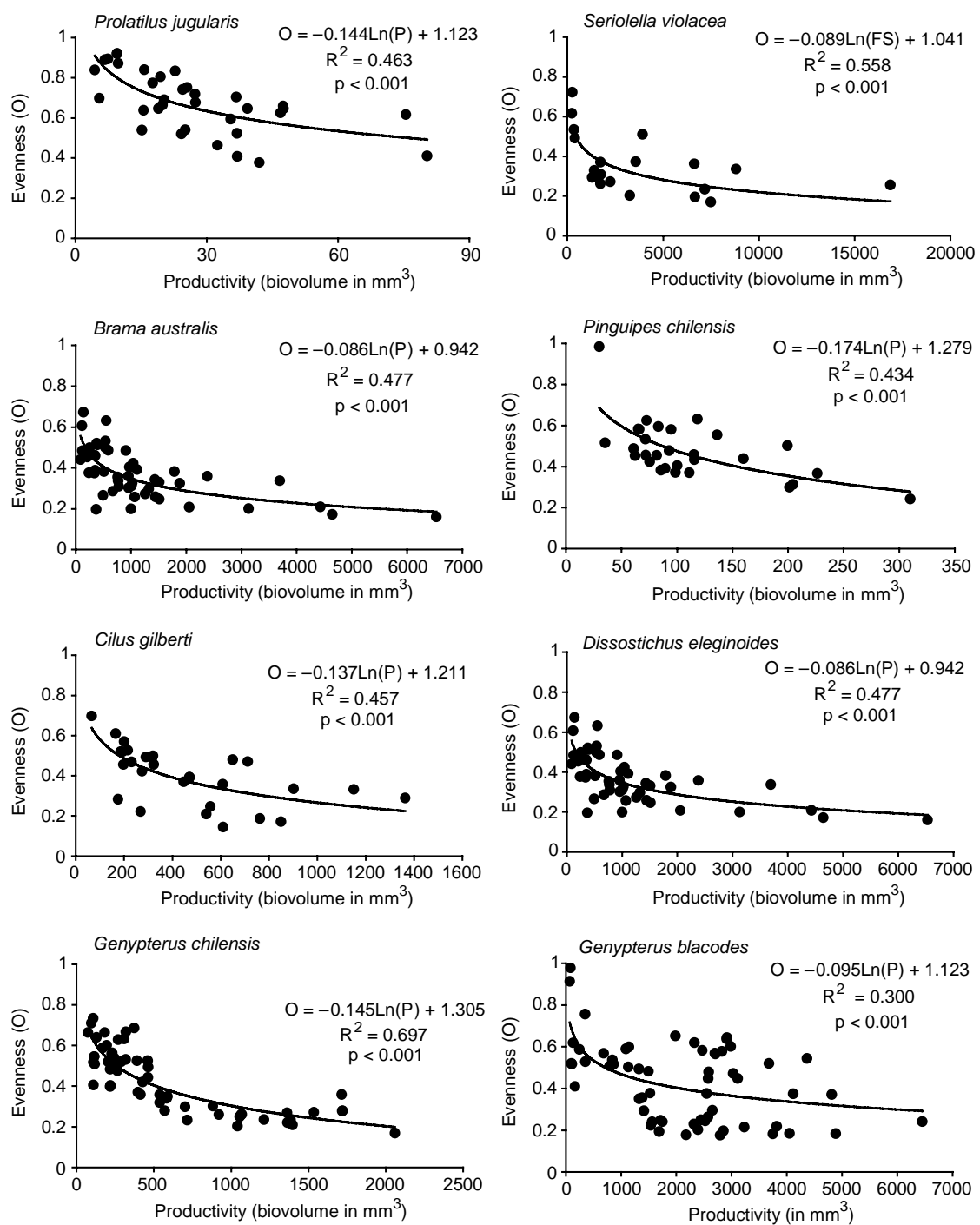

\section{Discussion}

\section{Richness-productivity relationships}

We found that richness, productivity and stability are clearly independent from the number of hosts examined (Table 2). Among the 15 host species, five show no relation, one shows a hump shaped curve and the rest show positive monotonic relations between productivity and diversity (Table 3). Nevertheless if host size strongly influences productivity and richness (Poulin 2000), one can argue that the positive relations we obtain between richness and productivity are only an artefact of the large spectrum of host body sizes. If small fish have low parasite species richness and low productivity for parasite communities whereas high richness and productivity characterise large fish, this could explain the high percentage of linear positive relationships we observed.
We reject this argument for two reasons. First, the six host species for which we did not get a positive monotonic relation are not species with the lowest

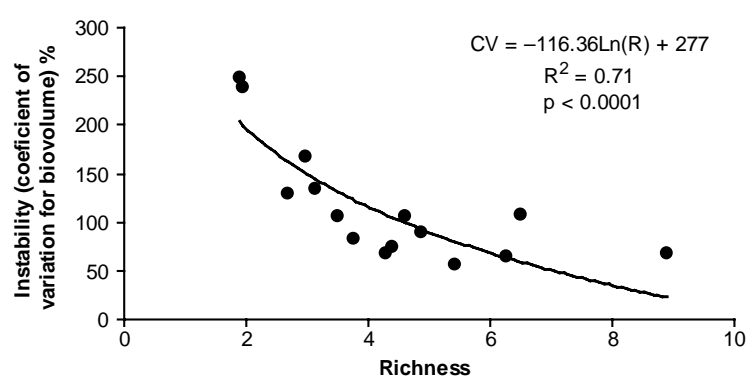

Fig. 4. Relationship between instability of the parasite community (coefficient of variation in parasite biovolume) and parasite species richness across 15 fish host species. 
Table 4. C-score and V-ratio indices for the 15 fish host species ( $\mathrm{H}$ and $\mathrm{L}$ for significantly higher and lower indices than expected by chance), the associated standardized effect size (SES) and the new C-score indices.

\begin{tabular}{|c|c|c|c|c|c|}
\hline Host species & C-score & SES C-score & C-score ${ }_{\mathrm{s}}$ & V-ratio & SES V-ratio \\
\hline Dissostichus eleginoides & $68.00^{\text {ns }}$ & 1.50 & 2.83 & $1.36^{\mathrm{H}^{*}}$ & 1.82 \\
\hline Merluccius australis & $2691.39^{\mathrm{H}^{* * *}}$ & 2.85 & 1.61 & $0.85^{\mathrm{L}^{*}}$ & -2.07 \\
\hline Macruronus magellanicus & $200.02^{\text {ns }}$ & 1.57 & 0.93 & $1.88^{\mathrm{H}^{* * *}}$ & 8.17 \\
\hline Eleginops maclovinus & $115.39^{\mathrm{H}^{* * *}}$ & 10.09 & 2.05 & $0.84^{\mathrm{ns}}$ & -0.52 \\
\hline Cilus gilberti & $14.39^{\text {ns }}$ & -0.19 & 1.71 & $1.88^{\mathrm{H}^{* * *}}$ & 3.38 \\
\hline Prolatilus jugularis & $16.32^{\text {ns }}$ & -0.67 & 1.33 & $1.39^{\mathrm{ns}}$ & 1.73 \\
\hline Pinguipes chilensis & $13.28^{\text {ns }}$ & 0.51 & 1.58 & $1.21^{\mathrm{ns}}$ & 0.82 \\
\hline Brama australis & $9.43^{\mathrm{ns}}$ & 1.50 & 1.39 & $1.29^{\mathrm{ns}}$ & 1.09 \\
\hline Thyrsites atun & $5.60^{\mathrm{H}^{*}}$ & 1.84 & 1.73 & $0.99^{\mathrm{ns}}$ & 1.13 \\
\hline Scomber japonicus & $81.96^{\mathrm{ns}}$ & 0.51 & 1.77 & $0.60^{\mathrm{L}^{*}}$ & -1.77 \\
\hline Seriolella violacea & $11.389^{\mathrm{ns}}$ & -0.92 & 2.85 & $1.35^{\mathrm{ns}}$ & 1.17 \\
\hline Stromateus stellatus & $9.62^{\text {ns }}$ & -0.12 & 0.78 & $0.99^{\mathrm{ns}}$ & 0.56 \\
\hline Genvpterus maculatus & $126.87^{\mathrm{ns}}$ & 0.39 & 3.52 & $0.63^{\mathrm{L}^{*}}$ & -2.12 \\
\hline Genvpterus chilensis & $150.67^{\mathrm{ns}}$ & 1.67 & 4.19 & $0.56^{\mathrm{L}^{* *}}$ & -2.51 \\
\hline Genypterus blacodes & $115.69^{\mathrm{H}^{* * *}}$ & 3.67 & 3.21 & $1.00^{\mathrm{ns}}$ & 0.04 \\
\hline
\end{tabular}

$*: \mathrm{p}<0.05 ; * *: \mathrm{p}<0.01 ;{ }^{* * *}: \mathrm{p}<0.0001 ;{ }^{\mathrm{ns}} \mathrm{p}>0.05$.

coefficients of variation in body size (Table 1). Secondly, after correcting for fish size, the positive monotonic relation and the absence of relation remain the main patterns observed.

If we focus on the results corrected for fish body sizes, we see that the two host species for which we get a hump shaped curve (M. australis and $S$. japonicus) are host species harbouring a parasite community with a significantly lower V-ratio than expected based on a null model (Table 4). Moreover, the two other host species with a lower V-ratio than expected (G. maculatus and
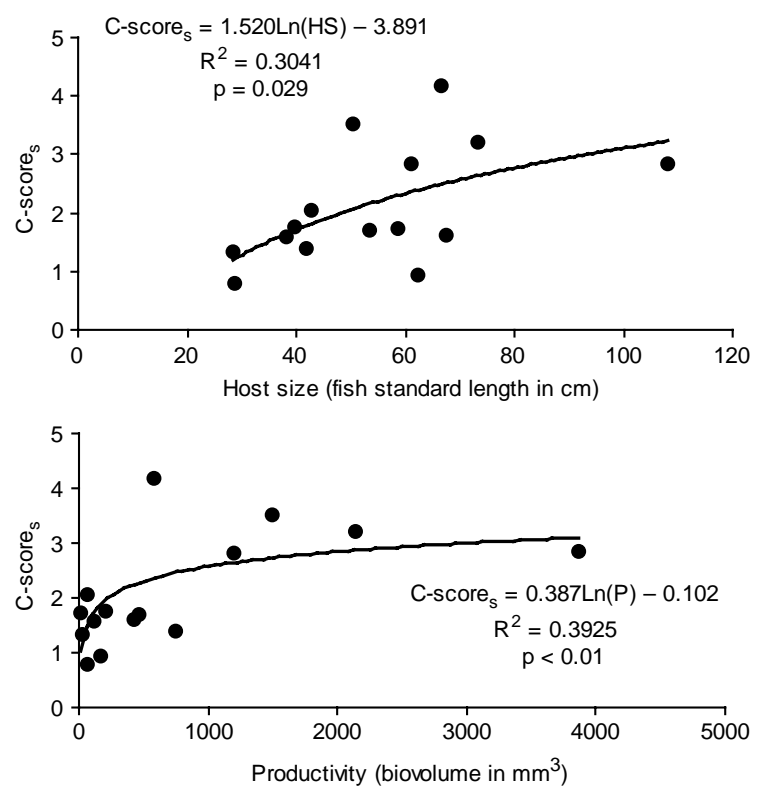

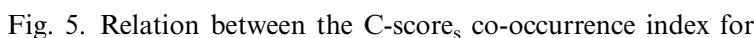
parasite species and both the mean standard length of the 15 fish species examined and the parasite community productivity.
G. chilensis) present an absence of relation between richness and productivity. In other words, when "niche limitation" occurs, i.e. when the number of coexisting species is limited, richness is not higher for high levels of productivity (biovolume) but can be unrelated to productivity or higher at intermediate levels of productivity. The most common explanation of the humpshaped curve is given by Grime (1973) and Huston (1979) as the "intermediate-disturbance hypothesis" which stipulates that at high level of biomass/productivity and low level of disturbance, only the best competitors persist, at low level of productivity and high level of disturbance, a few specialist or opportunistic species persist, whereas at intermediate levels coexistence of species is favoured. Thus, competition for resources could explain this common curve. In $S$. japonicus, however, the C-score, high when competition occurs (structured communities; Gotelli 2000, Gotelli and Rohde 2002), is not significantly different from that expected from a null model. Also, parasite communities of E. maclovinus and $T$. atun hosts present a significantly higher C-score than expected by chance (high competition leading to a high number of checkerboard units in the occurrence matrix and negative covariance among species) but the relation between productivity and richness is monotonic positive. Thus, while a lower V-ratio (strong limitation in the number of species) is related to the absence of linear increase of richness with productivity, a high $\mathrm{C}$-score is not.

Recently, VanderMeulen et al. (2001) suggested that in intermediate productivity environments, there are more types of successful adaptations; this is the evolutionary tradeoffs hypothesis: "diversity is highest at intermediate productivities because a tradeoff between intense competition at high productivities and high stress at low productivities allows more species to be 
successful by adapting to an intermediate environment". This hypothesis seems particularly relevant for parasite communities, constructed with a niche filling process by accumulation of new species. Thus we retain this hypothesis for the two humpshaped curves we obtain, i.e. medium levels of productivity are open to new parasite species whereas competition through niche limitation prevents high richness from occurring at high levels of productivity.

For $40 \%$ of the host species (Table 3), we observe a positive monotonic relation between residuals of richness and residuals of productivity. Except for M. magellanicus, the V-ratio is not significant and except for E. maclovinus and $T$. atun the $\mathrm{C}$-score is not significant for the parasite community of these 6 host species (Table 4). Thus, the parasite communities are largely unstructured as suggested by many earlier studies (Gotelli and Rohde 2002). If we look for the driver of the relation between richness and productivity, the absence of structure in the community is an argument in favour of species richness being the driver. When the community is not structured or not clearly ruled by interactions we can hypothesize that the increasing size of the host may allow more niche space available for the independent establishment of new parasites species, which in turn would lead to greater parasite biomass. This greater biomass or productivity is not limiting the number of species and richness can increase linearly with host size.

This positive link between richness and productivity is explained by various hypotheses (Tilman 1999, Yachi and Loreau 1999, Loreau 2000, Fridley 2001, Kinzig et al. 2002). The most interesting one for parasite communities involves the complementarity effect. The idea that the number of species with different functional niches and different resource requirements increases the productivity of the community seems very attractive for parasite systems. Greater parasite richness may allow more niches to be exploited in the body of the host and a higher proportion of the host to be consumed, potentially increasing the parasite community biomass. The regular way in which several species are arranged spatially in rich communities of gastrointestinal parasites, although interpreted as evidence of interactive niche segregation, also suggests a certain complementarity in resource use (Bush and Holmes 1986, Stock and Holmes 1988).

\section{Relationship between evenness and fish size or productivity}

For the evenness-productivity relationship, the pattern is surprisingly very consistent across the eight host species considered (Fig. 3). As suggested by Drobner et al. (1998), we found a strong negative log linear relation between evenness and productivity for parasite communities. Drobner et al. (1998) and Laird et al. (2003) found consistently the same kind of negative relation between plant diversity and the photosynthetic biomass. To explain this relation in parasite communities we use the arguments developed by Drobner et al. (1998). In high stress environments or low productivity systems, we might see higher extinction rates because of greater temporal variability in population size and hence a higher risk of extinction for rare species (Rosenzweig 1971). In these environments, available resources are scarce so rare species cannot form viable populations and might disappear (Rosenzweig and Abramsky 1993). When rare species go extinct, the evenness of the remaining species increases (Drobner et al. 1998). In low stress or high productivity environments, strong compe ${ }^{\text {ns }}$ tition among species occurs (Grime 1973), thus 'competitively dominant' species tend to increase their abundance and decrease the relative abundance of rare ones.

However, even if we obtain the same patterns as Drobner et al. (1998) it is difficult to retain their hypotheses for our result because metazoan parasites do not multiply on their host; an infrapopulation increases via larval recruitment from the external environment, independently of productivity or biovolume of the parasite community. We propose a new hypothesis based on host immunity. For low parasite productivity levels (left hand side in Fig. 2), the host may be highly resistant to parasite invasion or establishment and thus we have low rates of successful infection in these hosts. If low infection rates apply to parasite individuals randomly, rare species will be affected more severely; and their failure to establish will result in greater evenness of the parasite species that were successful. For high productivity parasite communities (hosts with high biovolume of parasites), the host may be more susceptible to infection by parasites and more able to harbor new parasite species; thus some rare parasite species can establish, which decreases overall evenness. This 'dominanceresistance' hypothesis could explain the negative loglinear relationship we obtained between evenness and productivity.

Our result on evenness-productivity relationship seems totally opposite to the result obtained by Wilsey and Polley (2002) and by Wilsey and Potvin (2000) who argued that evenness increases productivity and decreases rates of invasion but are in accordance with more recent results obtained by Mulder et al. (2004) arguing that the relationship between evenness and biomass across all plots was negative. Reconciling their experimental results and ours may require manipulative experiments on parasite communities. 


\section{Richness-stability relationship}

Stability has recently been the focus of much attention and its relation with richness lead to controversial results clearly summarized in McCann (2000) and Tilman (1999). In our study, richness is negatively correlated with the coefficient of variation in productivity among replicates (Table 2) and this relation is clearly log linear decreasing (Fig. 4). Our result is in accordance with other studies (Tilman and Downing 1994, Tilman 1996, Tilman et al. 1996, 1998, McGrady-Steed et al. 1997, Doak et al. 1998, Ives et al. 1999, McGrady-Steed and Morin 2000, Ives and Hughes 2002). Nevertheless coexistence rules including competitive interactions are certainly playing a major role in this relation (Tilman 1999, Ives and Hughes 2002, Pfisterer and Schmid 2002).

Our result needs an explanation and of the classical hypotheses concerning diversity-stability relationships, the "averaging portfolio" hypothesis seems the most likely candidate. The portfolio effect could certainly explain the stability of very rich parasite communities, i.e. the higher the number of different parasite populations, the more changes in the abundance of one of these can be compensated by others.

\section{Relations between structure and functioning}

The most important relationships between structure indices and functioning in parasite communities are the richness-stability and the $\mathrm{C}$-score s $_{\mathrm{s}}$-productivity relations (Table 2). Although the former (discussed above) is not too surprising, the latter have never been reported before. The C-scores, i.e. the number of checkerboard units or the segregation of parasite species, increases linearly with both host body size and infracommunity productivity. In other words, when the size of the host and total parasite biovolume increase the parasite community tends to be more structured (via competition or other structuring processes). In parasite communities, however, competition is certainly not strong enough to lead to exclusion. For this reason we do not get a hump shaped curve as the theory predicts but a linear increase between diversity and productivity (Poulin et al. 2003). This is in overall agreement with several earlier studies that have questioned the importance of competition in structuring parasite communities (Poulin 1996, Worthen and Rohde 1996, Morand et al. 2002).

Three results concerning the V-ratio index are surprising with respect to earlier studies (Gotelli 2000, Gotelli and Ellison 2002a, 2002b, Gotelli and Rohde 2002, Sanders et al. 2003) because if the result is different from the null hypothesis, we would expect the V-ratio index to be lower than that corresponding to randomness. Nevertheless we obtained for D. eleginoides, M. magellanicus and C. gilberti V-ratio values significantly higher than expected under the null hypothesis (Table 4). In other words, the variability in the mean parasite species richness per individual host is higher than expected by chance, suggesting a very high aggregation of species. We suspect this result to be an artefact due to the variability in the size of the fish examined. If the sizes of the individuals examined vary greatly among replicates and if this size is largely and positively influencing parasite species richness (Poulin 2000), then it is not surprising to get a strong aggregation of species as demonstrated by the V-ratio indices. We can observe that the two species with a SES V-ratio significantly higher than expected by chance (D. eleginoides and C. gilberti, Table 4) have high coefficients of variation in fish size compared to other host species (Table 1). We suggest that, because of this spurious effect, only V-ratio values lower than expected should be considered further.

\section{Conclusion}

Our study provides the first application of ideas on biodiversity and ecosystem functioning, developed for free living communities, to communities of parasites living on hosts. Parasite communities offer several advantages over other community types, and the results we obtained allow interesting parallels with those found with free living communities. First, we found that as community productivity increased among parasite infracommunities, species richness often, but not always, increased linearly, whereas species evenness consistently decreased. Second, among parasite communities from different host species, stability (measured as variation in productivity or biomass among host individuals) increased as species richness increased. As emphasized by Naeem and Wright (2003), the effect of biodiversity on ecosystem processes is now widely accepted and we must now determine which facet of biodiversity is acting and how. Third, using community structure indices, we found that when the total parasite biovolume (productivity) increases, the parasite community tends to be more structured (via competition or other structuring processes); a limitation of species richness may thus occur, leading to either no or a humpshaped relationship between richness and productivity. Among the factors influencing the diversity-productivity patterns (disturbance, scale or niche specialization) the history of community assembly, as recently demonstrated by Fukami and Morin (2003), could be the most important one in parasite communities, where species introduction is sequential. Thus, the order in which species join an infracommunity could modify the host responses and all subsequent processes in the community; an experimental approach will be required to evaluate this possibility. 
Acknowledgements - This study was supported by Grant Fondecyt 1980442 to M. George-Nascimento. R. Poulin is supported by a James Cook Research Fellowship from the Royal Society of New Zealand.

\section{References}

Aarssen, L. W. 1997. High productivity in grassland ecosystems: effected by species diversity or productive species? - Oikos 80: $183-184$.

Armsworth, P. R. and Roughgarden, J. E. 2003. The economic value of ecological stability. - Proc. Natl Acad. Sci. USA 100: 7147-7151.

Bai, Y. F., Han, X. G., Wu, J. G. et al. 2004. Ecosystem stability and compensatory effects in the inner Mongolia grassland. - Nature 431: 181-184.

Bond, E. M. and Chase, J. M. 2002. Biodiversity and ecosystem functioning at local and regional spatial scales. - Ecol. Lett. 5: 467-470.

Bulla, L. 1994. An index of evenness and its associated diversity measure. - Oikos 70: 167-171.

Bush, A. O. and Holmes, J. C. 1986. Intestinal helminths of lesser scaup ducks: an interactive community. - Can. J. Zool. 64: 142-152.

Bush, A. O., Lafferty, K. D., Lotz, J. M. et al. 1997. Parasitology meets ecology on its own terms: Margolis et al revisited. - J. Parasitol. 83: 575-583.

Chase, J. M. and Leibold, M. A. 2002. Spatial scale dictates the productivity-biodiversity relationship. - Nature 416: 427-430.

Doak, D. F., Bigger, D., Harding, E. K. et al. 1998. The statistical inevitability of stability-diversity relationships in community ecology. - Am. Nat. 151: 264-276.

Drobner, U., Bibby, J., Smith, B. et al. 1998. The relation between community biomass and evenness: what does community theory predict, and can these predictions be tested? - Oikos 82: 295-302.

Fridley, J. D. 2001. The influence of species diversity on ecosystem productivity: how, where, and why? - Oikos 93: $514-526$.

Frontier, S. 1985. Diversity and structure in aquatic ecosystems. - Mar. Biol. Annu. Rev. 23: 253-312.

Fukami, T. and Morin, P. J. 2003. Productivity-biodiversity relationships depend on the history of community assembly. - Nature 424: 423-426.

George-Nascimento, M., Garcías, F. and Muñoz, G. 2002. Parasite body volume and infracommunity patterns in the southern pomfret Brama australis (Pisces: Bramidae). - Rev. Chilena Hist. Nat. 75: 835-839.

George-Nascimento, M., Muñoz, G., Marquet, P. et al. 2004. Testing the energetic equivalence rule with helminth endoparasites of vertebrates. - Ecol. Lett. 7: 527-531.

Givnish, T. J. 1994. Does diversity beget stability? - Nature 371: $113-114$.

Gotelli, N. J. 2000. Null model analysis of species co-occurrence patterns. - Ecology 81: 2606-2621.

Gotelli, N. J. and Graves, G. R. 1996. Null models in ecology. - Smithsonian Institution Press.

Gotelli, N. J. and Entsminger, G. L. 2001. Swap and fill algorithms in null model analysis: rethinking the knight's tour. - Oecologia 129: 281-291.

Gotelli, N. J. and Ellison, A. M. 2002a. Assembly rules for New England ant assemblages. - Oikos 99: 591-599.

Gotelli, N. J. and Ellison, A. M. 2002b. Biogeography at a regional scale: determinants of ant species density in New England bogs and forests. - Ecology 83: 1604-1609.

Gotelli, N. J. and McCabe, D. J. 2002. Species co-occurrence: a meta-analysis of J. M. Diamond's assembly rules model. - Ecology 83: 2091-2096.

Gotelli, N. J. and Rohde, K. 2002. Co-occurrence of ectoparasites of marine fishes: a null model analysis. - Ecol. Lett. 5: 86-94.
Gotelli, N. J. and Entsminger, G. L. 2003. Swap algorithms in null model analysis. - Ecology 84: 532-535.

Grime, J. P. 1973. Competitive exclusion in herbaceous vegetation. - Nature 242: 344-347.

Holmes, J. C. and Price, P. 1986. Communities of parasites. - In: Anderson, D. J. and Kikkawa, J. (eds), Community ecology, pattern and process. Blackwell Scientific, pp. 187213.

Huston, M. A. 1979. A general hypothesis of species diversity. - Am. Nat. 113: 81-101.

Huston, M. A. 1997. Hidden treatments in ecological experiments: re-evaluating the ecosystem function of biodiversity. - Oecologia 110: 449-460.

Huston, M. A. and DeAngelis, D. L. 1994. Competition and coexistence: the effects of resource transport and supply rates. - Am. Nat. 144: 954-977.

Ives, A. R. and Hughes, J. B. 2002. General relationships between species diversity and stability in competitive systems. - Am. Nat. 159: 388-395.

Ives, A. R., Gross, K. and Klug, J. L. 1999. Stability and variability in competitive communities. - Science 286: 542-544.

Kinzig, A. P., Pacala, S. W. and Tilman, D. 2002. The functional consequences of biodiversity: empirical progress and theoretical extensions. - Princeton Univ. Press.

Laird, R. A., Pither, J. and Aarssen, L. W. 2003. Species evenness, not richness has a consistent relationship with productivity in old-field vegetation. - Community Ecol. 4: $21-28$.

Leps, J. 2004. Variability in population and community biomass in a grassland community affected by environmental productivity and diversity. - Oikos 107: 64-71.

Loreau, M. 2000. Biodiversity and ecosystem functioning: recent theoretical advances. - Oikos 91: 3-17.

Loreau, M. and Hector, A. 2001. Partitioning selection and complementarity in biodiversity experiments. - Nature 412: $72-76$.

Loreau, M., Naeem, S., Inchausti, P. et al. 2001. Ecologybiodiversity and ecosystem functioning: current knowledge and future challenges. - Science 294: 804-808.

Ludwig, J. A. and Reynolds, J. F. 1988. Statistical ecology. A primer on methods and computing. - Wiley.

Macarthur, R. H. and Levins, R. 1964. Competition habitat selection + character displacement in patchy environment. - Proc. Natl Acad. Sci. USA 51: 1207.

Mackey, R. L. and Currie, D. J. 2001. The diversity-disturbance relationship: is it generally strong and peaked? - Ecology 82: 3479-3492.

Magurran, A. E. 1988. Ecological diversity and its measurement. - Princeton Univ. Press.

Manly, B. F. J. 1998. Randomization, bootstrap and Monte Carlo methods in biology. - Chapman and Hall.

McCann, K. S. 2000. The diversity-stability debate. - Nature 405: $228-233$.

McGrady-Steed, J. and Morin, P. J. 2000. Biodiversity, density compensation, and the dynamics of populations and functional groups. - Ecology 81: 361-373.

McGrady-Steed, J., Harris, P. M. and Morin, P. J. 1997. Biodiversity regulates ecosystem predictability. - Nature 390: $162-165$.

Mitchell-Olds, T. and Shawn, R. G. 1987. Regression analysis of natural selection: statistical influence and biological interpretation. - Evolution 41: 1149-1161.

Mittelbach, G. G., Steiner, C. F., Scheiner, S. M. et al. 2001. What is the observed relationship between species richness and productivity? - Ecology 82: 2381-2396.

Mouillot, D. and Wilson, J. B. 2002. Can we tell how a community was constructed? A comparison of five evenness indices for their ability to identify theoretical models of community construction. - Theor. Popul. Biol. 61: 141-151

Mouillot, D., Lepretre, A., AndreiRuiz, M. C. et al. 2000. The fractal model: a new model to describe the species accumulation process and relative abundance distribution (RAD). - Oikos 90: 333-342. 
Mouillot, D., Culioli, J. M., Wilson, J. B. et al. 2001. Number, length, area or biomass: can there be intermediates? - Ecoscience 8: 264-267.

Mouillot, D., George-Nascimento, M. and Poulin, R. 2003. How parasites divide resources: a test of the niche apportionment hypothesis. - J. Anim. Ecol. 72: 757-764.

Morand, S. 2000. Wormy world: comparative tests of theoretical hypotheses on parasite species richness. - In: Poulin, R., Morand, S. and Skorping, A. (eds), Evolutionary biology of host-parasite relationships: theory meets reality. Elsevier, pp. 63-79.

Morand, S., Poulin, R., Rohde, K. and Hayward, C. J. 1999. Aggregation and species coexistence of ectoparasites of marine fishes. - Int. J. Parasitol. 29: 663-672.

Morand, S., Rohde, K. and Hayward, C. 2002. Order in ectoparasite communities of marine fish is explained by epidemiological processes. - Parasitology 124 (Suppl.): S57-S63.

Mulder, C. P. H., Bazeley-White, E., Dimitrakopoulos, P. G. et al. 2004. Species evenness and productivity in experimental plant communities. - Oikos 107: 50-63.

Naeem, S. 2002. Disentangling the impacts of diversity on ecosystem functioning in combinatorial experiments. - Ecology 83: 2925-2935.

Naeem, S. and Hawkins, B. A. 1994. Minimal community structure: how parasitoids divide resources. - Ecology 75: $79-85$.

Naeem, S. and Wright, J. P. 2003. Disentangling biodiversity effects on ecosystem functioning: deriving solutions to a seemingly insurmountable problem. - Ecol. Lett. 6: 567-579.

Naeem, S., Knops, J. M. H., Tilman, D. et al. 2000. Plant diversity increases resistance to invasion in the absence of covarying extrinsic factors. - Oikos 91: 97-108.

Pfisterer, A. B. and Schmid, B. 2002. Diversity-dependent production can decrease the stability of ecosystem functioning. - Nature 416: 84-86.

Polley, H. W., Wilsey, B. J. and Derner, J. D. 2003. Do species evenness and plant density influence the magnitude of selection and complementarity effects in annual plant species mixtures? - Ecol. Lett. 6: 248-256.

Poulin, R. 1996. Richness, nestedness, and randomness in parasite infracommunity structure. - Oecologia 105: 545-551.

Poulin, R 1997. Species richness of parasite assemblages: evolution and patterns. - Annu. Rev. Ecol. Syst. 28: 341-358.

Poulin, R. 1998. Evolutionary ecology of parasites: from individuals to communities. - Chapman and Hall.

Poulin, R. 2000. Variation in the intraspecific relationship between fish length and intensity of parasitic infection: biological and statistical causes. - J. Fish Biol. 56: 123-137.

Poulin, R., Mouillot, D. and George-Nascimento, M. 2003. The relationship between species richness and productivity in metazoan parasite communities. - Oecologia 137: 277-285.

Purvis, A. and Hector, A. 2000. Getting the measure of biodiversity. - Nature 405: 212-219.

Rajaniemi, T. K. 2003. Explaining productivity-diversity relationships in plants. - Oikos 101: 449-457.

Robson, D. S. 1972. Appendix: statistical tests of significance. - J. Theor. Biol. 34: 350-352.

Rohde, K. 1991. Intra- and interspecific interactions in low density populations in resource-rich habitats. - Oikos 60: 91-104.

Rosenfeld, J. S. 2002. Functional redundancy in ecology and conservation. - Oikos 98: 156-162.

Rosenzweig, M. L. 1971. Paradox of enrichment: destabilization of exploitation ecosystems in ecological time. - Science 171: 385-387.

Rosenzweig, M. L. and Abramsky, Z. 1993. How are diversity and productivity related? - In: Ricklefs, R. E. and Schluter, D. (eds), Species diversity in ecological communities. Univ. of Chicago Press, pp. 52-65.

Sanders, N. J., Gotelli, N. J., Heller, N. E. et al. 2003. Community disassembly by an invasive species. - Proc. Natl Acad. Sci. USA 100: 2474-2477.
Schluter, D. 1984. A variance test for detecting species associations, with some example applications. - Ecology 65: $998-$ 1005.

Schmid, B. 2002. The species richness-productivity controversy. - Trends Ecol. Evol. 17: 113-114.

Smith, B. and Wilson, J. B. 1996. A consumer's guide to evenness indices. - Oikos 76: 70-82.

Stock, T. M. and Holmes, J. C. 1988. Functional relationships and microhabitat distributions of enteric helminths of grebes (Podicipedidae): the evidence for interactive communities. - J. Parasitol. 74: 214-227.

Stone, L. and Roberts, A. 1990. The checkerboard score and species distributions. - Oecologia 85: 74-79.

Stubbs, W. J. and Wilson, J. B. 2004. Evidence for limiting similarity in a sand dune community. - J. Ecol. 92: 557-567.

Tilman, D. 1996. Biodiversity: population versus ecosystem stability. - Ecology 77: 350-363.

Tilman, D. 1999. The ecological consequences of changes in biodiversity: a search for general principles. - Ecology 80: 1455-1474.

Tilman, D. and Downing, J. A. 1994. Biodiversity and stability in grasslands. - Nature 367: 363-365.

Tilman, D., Lehman, C. L. and Bristow, C. E. 1998. Diversitystability relationships: statistical inevitability or ecological consequence? - Am. Nat. 151: 277-282.

Tilman, D., Wedin, D. and Knops, J. 1996. Productivity and sustainability influenced by biodiversity in grassland ecosystems. - Nature 379: 718-720.

Tokeshi, M. 1993. Species abundance patterns and community structure. - Adv. Ecol. Res. 24: 111-186.

VanderMeulen, M. A., Hudson, A. J. and Scheiner, S. M. 2001. Three evolutionary hypotheses for the humpshaped productivity-diversity curve. - Evol. Ecol. Res. 3: 379-392.

Waide, R. B., Willig, M. R., Steiner, C. F. et al. 1999. The relationship between productivity and species richness. - Annu. Rev. Ecol. Syst. 30: 257-300.

Wardle, D. A. 2001a. Experimental demonstration that plant diversity reduces invasibility - evidence of a biological mechanism or a consequence of sampling effect? - Oikos 95: $161-170$.

Wardle, D. A. 2001b. No observational evidence for diversity enhancing productivity in Mediterranean shrublands. - Oecologia 129: 620-621.

Wardle, D. A. and Grime, J. P. 2003. Biodiversity and stability of grassland ecosystem functioning. - Oikos 100: 622-623.

Wardle, D. A., Bonner, K. I. and Nicholson, K. S. 1997. Biodiversity and plant litter: experimental evidence which does not support the view that enhanced species richness improves ecosystem function. - Oikos 79: 247-258.

Weiher, E. 1999. The combined effects of scale and productivity on species richness. - J. Ecol. 87: 1005-1011.

Wilsey, B. J. and Potvin, C. 2000. Biodiversity and ecosystem functioning: importance of species evenness in an old field. - Ecology 81: 887-892.

Wilsey, B. J. and Polley, H. W. 2002. Reductions in grassland species evenness increase dicot seedling invasion and spittle bug infestation. - Ecol. Lett. 5: 676-684.

Wilson, J. B. 1987. Methods for detecting nonrandomness in species co-occurrences-a contribution. - Oecologia 73: 579582.

Wilson, J. B. and Roxburgh, S. H. 1994. A demonstration of guild-based assembly rules for a plant community and determination of intrinsic guilds. - Oikos 69: 267-276.

Wilson, J. B. and Roxburgh, S. H. 2001. Intrinsic guild structure: determination from competition experiments. - Oikos 92: 189-192.

Worthen, W. B. and Rohde, K. 1996. Nested subset analyses of colonization-dominated communities: metazoan ectoparasites of marine fishes. - Oikos 75: 471-478.

Yachi, S. and Loreau, M. 1999. Biodiversity and ecosystem productivity in a fluctuating environment: the insurance hypothesis. - Proc. Natl Acad. Sci. USA 96: 1463-1468. 